\title{
Minimum dietary diversity and associated factors among 6-23 months children in rural community, Southern Ethiopia: a cross-sectional study
}

\section{Birhanu G/Wold}

Kenbata Tembaro zonal health department, Durame, Ethiopia

\section{Shimelash Bitew}

Wolaita Sodo University

Temesgen Bati ( $\nabla$ temesgenbati@gmail.com )

Wolaita Sodo University https://orcid.org/0000-0002-3754-6061

Tsegaye Demssie

Wolaita Sodo University

\section{Research}

Keywords: Kacha Bira district, minimum dietary diversity, 6-23 months age children

Posted Date: March 10th, 2020

DOI: https://doi.org/10.21203/rs.3.rs-16632/v1

License: (a) (i) This work is licensed under a Creative Commons Attribution 4.0 International License. Read Full License 


\section{Abstract}

Background: Lack of dietary diversity especially for children 6-23 months is critical because they require energy and nutrient-dense foods for both physical, mental growth and development. However, in many low-income countries particularly in rural area, at least meeting the minimum dietary diversity standard has been a major challenge. Therefore, this study aimed to assess minimum dietary diversity and associated factors among 6-23 months children in rural community of Kacha Bira district, Southern Ethiopia.

Methods: A community based cross-sectional study was employed on 623 children aged 6-23 months. Two stages cluster sampling method was conducted to select study population. Pre-tested and interviewer administered questionnaire was used for data collection. Data were entered and cleaned by Epi data 3.1, then exported to SPSS (Statistical Package for Social Sciences) version 20 for statistical analysis. Bivariate and multivariable logistic regression was employed using a p-value $<0.25$ and $<0.05$, respectively.

Results: In this study, the day before data collection $46.1 \%$ (95\% Cl: 42.1-50.0) of 6-23 months children were fed on adequately diversified diets. Maternal age $18-24$ years [AOR=3.68(95\% Cl: 1.18, 6.22)], postnatal care follow up [AOR=8.8 (95\% Cl: 5.17, 14.98)], children 6-11 months age [AOR=2.04(95\%Cl: 1.24 , $3.39)]$ and being household food secured [AOR=3.64(95\% Cl: $2.27,5.84)]$ were associated with dietary diversity.

Conclusions: In the study area less than half of 6-23 months children were fed on adequately diversified diets, which is very low. All mothers should be encouraged to make postnatal care follow up and measures should take to improve food security of the household.

\section{Background}

World Health Organization (WHO) define; minimum dietary diversity (MDD) is proportion of children 6-23 months of age who received at least 4 of seven recommended food groups during the previous day. Grains, roots and tubers, legumes and nuts, dairy products (milk, yogurt, cheese), flesh foods (meat, fish, poultry and organ meats), eggs, vitamin-A rich fruits and vegetables and other fruits and vegetables were named as seven recommended food groups(1).

Timely measuring and improving feeding practices is critical in children 6-23 months of age. However, this has been hindered due to the lack of evidence and consensus on simple indicators of appropriate feeding practices, thereby constraining improvements in infant and young child nutritional outcomes(1).

According to International Food Policy Research Institute, dietary diversity is often assumed to be a proxy for nutrient adequacy and it is a promising measurement tool of appropriate feeding practices(2). 
Additionally, WHO indicated MDD among the core indicators of infant and young child feeding practices(3).

Although the national nutrition program of Ethiopia set strategic objective to increase the proportion of children 6-23 months with minimum dietary diversity score from $5-40 \%$ by 2020 ; particularly in the first 1,000 days after a child's birth, which is a critical period(4). But, Ethiopia Demographic and Health Survey (EDHS) of 2016 reported, only $14 \%$ of children provided with minimum dietary diversity(5). This report had shown that dietary diversity is still a major problem of the country.

To protect infants and young children from undernutrition particularly stunting and micronutrient deficiencies, and to decrease morbidity and mortality providing adequate diversity diet and meal frequency is required. Regarding malnutrition Ethiopia is one of the tops ranked among sub Saharan countries. To overcome and reduce this national undernutrition by at least one third among children less than five years of age by providing special attention to children under two years of age; appropriate feeding practices was recommended $(4,6)$. This could be measured by dietary diversity score, by this means the evidence might be used to improve infant and young child nutritional outcomes.

The study done in sub-Saharan Africa using this recommended indicator report as smaller proportions (21.0\%) of children 6-23 months of age satisfied the MDD in the area(7). A secondary analysis of EDHS 2011 finding had shown, only $10.8 \%$ of children aged 6-23 months in Ethiopia received adequate dietary diversity, which might negatively affect their growth and development(8).

In line with the above a secondary analysis of EDHS 2011 report, EDHS 2016 reported, the percentage of children provided with MDD was low (14\%). This finding had indicated that dietary diversity is still a major challenge of the country. Similarly, studies conducted in southern part of Ethiopia found only $10.6 \%, 43.2 \%$ and $23.3 \%$ of $6-23$ months aged children received adequately diversified diets $(5,9-11)$, which is below $50 \%$. However, the practice and associated factors vary from place to place, and recently there has been lack of adequate evidences regarding dietary diversity status and determinant factors in the rural community of sub-Saharan Africa.

Therefore, assessing minimum dietary diversity and associated factors among 6-23 months children in the rural community is important to provide information for all concerned body including researchers.

\section{Methods}

\section{Study design, setting and participants}

A community based cross-sectional study was conducted in rural community of Kacha Bira district, Southern Ethiopia. The district located $371 \mathrm{~km}$ South-West of the capital city Addis Ababa and divided in to 21 rural kebeles. According to Central Statistical Agency 2007 the district has 25,920 estimated households and 127,009 of a total population. As the District Health Office reported in 2018, the 
estimated number of infants and young children aged 6-23 months is 4,458 which are $3.5 \%$ of a total population. The district has one primary Hospital, 4 government Health Centers and 23 Health Posts(12).

According to Agriculture and natural resources office report the district is agro-ecologically classified into highlands $(2450 \mathrm{~m})$ and mid lands $(1845 \mathrm{~m})$. Agriculture is the main source of livelihood in the district and the area is vulnerable to food insecurity. Inset (false banana) and maize are staple foods, while cereals, roots and tubers, fruits and vegetables are also the common foods in the area(13). But there is no documented evidences regarding dietary diversity status and associated factors in the rural community of the district. Therefore, this study aimed to assess minimum dietary diversity and associated factors among 6-23 months children in the rural community of Southern Ethiopia. The source population was all 6-23 months children residing in the rural community of Kacha Bira district, while randomly selected 623 months children were study population.

\section{Sample size determination}

The sample size was determined using single population proportion formula with the following assumptions; $95 \%$ confidence level, 0.05 margin of error, 1.5 design effects, and $10 \%$ non-response rate. The proportion of MDD feeding from previous studies $(P=43.2 \%)(10)$. The final sample size determined was, 623.

\section{Sampling procedure}

Initially a total of 21 rural kebeles were stratified into highland and midland based on their predominating agro-ecological characteristics. Then from seven highland and fourteen midland kebeles; three and five kebeles were selected respectively by using simple random sampling technique. A total sample size of 623 children was proportionally allocated to population size of each selected kebeles. First survey was done to prepare for sampling frame of children 6-23 months. Finally, study subjects were selected by using systematic random sampling method. For those households $(\mathrm{HHs})$ with more than one eligible child lottery method was used to select one child. In case where the mother/care giver of the child was not found during the first visit, the $\mathrm{HH}$ was revisited for at least three times.

\section{Data collection tools, procedures and quality assurance}

A pre-tested and interviewer administered questionnaire was used. Questionnaire about sociodemographic and economic characteristics were adopted from EDHS 2016, while questionnaire on dietary diversity were adapted from WHO standardized questionnaire for infant and young child feeding practices. Household food insecurity access scale were used to assess the food security status of the $\mathrm{HH}$, and then measured and classified as recommended by the food and nutrition technical assistance guideline $(3,5,14)$.

The questionnaire was translated from English to Kembatisa language by language experts then backtranslated to English by another expert to maintain the consistency. After providing a four-day training data collection was done by ten diploma nurses and supervised by two public health officers. 


\section{Data management and analysis procedure}

Data was first cleaned and entered in Epi data 3.1, then exported to SPSS version 20 for statistical analysis. Descriptive statistics was done to describe the study subjects by using percentage, frequencies, and means. Then bivariate analysis between independent and dependent variables was performed using binary logistic regression to assess the presence of crude association at P-value $<0.25$. After checking for multicollinearity using variance inflation factor and Goodness of fit of the final model using Hosmer and Lemeshow, multivariable logistic regression analysis was done to adjust for possible confounding variables. In the meantime, P-value $<0.05$ with a $95 \%$ confidence interval $(\mathrm{Cl})$ for adjusted odds ratio (AOR) was used in judging the significance of the associations.

\section{Operational definitions}

\section{Minimum dietary diversity}

Proportion of children with 6-23 months of age who received foods from four or more food groups of the seven food groups during the previous day is considered as adequate and three and blow is considered inadequate (low).The seven recommended food groups are grains, roots and tubers, legumes and nuts, dairy products, flesh foods (meat, fish, poultry and organ meats), eggs, vitamin-A rich fruits and vegetables and other fruits and vegetables(1).

\section{Food security}

Exists when all people, at all times, have physical, social and economic access to sufficient, safe and nutritious food which meets their dietary needs and food preferences for an active and healthy life(14).

\section{Food insecurity}

Is a situation that exists when people lack secure access to sufficient amounts of safe and nutritious food for normal growth and development and an active and healthy life (14).

\section{Results}

\section{Socio-demographic and economic characteristics of mothers}

A total of 616 mothers paired with 6-23 months children were included in the study which makes the response rate of $98.87 \%$. The mean age of mothers was 29 ( \pm 7 SD) years. Most mothers 610 (99\%) were married. Concerning the occupational status of the mothers, $529(85.9 \%)$ were house wives. Of total mothers, only 60 (9.7\%) were attended college/university. Of all, $436(70.8 \%)$ and 69 (11.2\%) mothers were married to husband who is farmer in his occupation and attended college/university respectively. Concerning parity and family size, $295(47.9 \%)$ and 377 (61.2\%) of mothers had 2-4 live born children and 
4-6 members of family. Four hundred fifty-three (73.5\%) of the families earn less than 1000ETB per a month [Table 1].

\section{Household food security status}

Four hundred thirty-six (70.8\%) of the mothers were from food secure HHs and the remaining $180(29.2 \%)$ were from food insecure HHs [Table 2].

\section{Own production and home gardening}

Four hundred thirty-two $(70.1 \%)$ had a plot land for home gardening. Four hundred fifty-five $(73.9 \%)$ of the HHs had livestock. From the respondents, 576 (93.5\%) had agricultural land. Concerning the availability, 357 (58\%) and 246 (39.9\%) of respondents reported the availability of fruits and vegetables, and meat, milk and fish in the market respectively. One hundred seventy-seven $(28.7 \%)$ of the respondents had been getting milk from their own cow and $155(25.2 \%)$ had been getting eggs from their own chicken [Table 3].

\section{Maternal Health Care Services}

Three hundred fifty-three (57.3\%) mothers gave birth at health center. Almost all mothers, $604(98.1 \%)$ had ANC (Antenatal Care) follow up at least once. Four hundred forty-one $(71.6 \%)$ mothers visited for PNC (Postnatal Care). Of 616 mothers, 283(45.9\%) followed radio programs regularly [Table 4].

\section{Characteristics of Indexed Child}

Three hundred sixteen (51.3\%) children were female. Two hundred twenty-nine (37.2\%) of the children were under age group of 6-11 months. The mean ( $\pm S D$ ) age of children was $14 \pm 5.2$ months. About half of the children (50.2\%) were within the 2-4 birth order. Concerning health status of the sampled children, 580 $(94.2 \%)$ were healthy within the last two weeks prior to data collection. Among 616 sampled children, 527(85.6\%) were vaccinated [Table 5].

\section{Twenty-four hours Dietary assessment}

From dietary diversity assessment using 24-hour recall, 284 [46.1\%, 95\% Cl: $42.1-50.0]$ of mothers/caregivers offered four or more food groups to their children. Thirteen (2\%) gave no food other than breast milk [Figure1]. Foods made from grains, cereals, roots and tubers were the highest, 596(96.8\%), to be consumed by the children followed by vitamin A rich fruits and vegetables which was consumed by $354(57.5 \%)$ of the children [Figure 2].

\section{Factors Associated with Dietary Diversity Feeding}

In bivariate logistic regression analysis, maternal age, maternal occupation, maternal education, paternal education, PNC follow up, child age, having livestock, getting milk from own cow, having plot for home 
gardening, getting egg from own chicken and $\mathrm{HH}$ food security status had $\mathrm{p}$ values of $<0.25$ [Table 6]. Therefore, they were candidate for multivariable logistic regression analysis.

After applying multivariable logistic regressions analysis, four variables were found to be significantly associated with dietary diversity at $p$ values of $<0.05$. Mothers in age group 18-24 years were 3.68 times more likely to give adequately diversified diet to their children than mothers who were older [AOR=3.68, $95 \% \mathrm{Cl}$ : $1.18,6.22$ ]. Mothers who had PNC follow up were 8.8 times more likely to give minimum acceptable dietary diversity to their children than mothers who did not have post-natal care follow up with the last pregnancy [AOR=8.8 95\% Cl:5.17, 14.98]. Mothers who had 6-11 months age group children were 2 times more likely to give minimum acceptable dietary diversity to their children than mothers of children with age of $18-23$ months old [AOR=2.04, 95\% Cl: 1.24, 3.39]. Mothers who were from food secured HHs were 3.64 times more likely to give minimum acceptable diversified diets to their children than mothers who were from food insecure $\mathrm{HHs}[\mathrm{AOR}=3.64,95 \% \mathrm{Cl}: 2.27,5.84]$ [Table 6].

\section{Discussion}

The overall of minimum acceptable dietary diversity in the study area was $46.1 \%$. Maternal age, PNC follow up, age of the child, and $\mathrm{HH}$ food security status were found the independent predictor of a minimum dietary diversity.

About forty six percent of children met the MDD in this study, which is relatively better compared to the national report (14\%), and findings from Southern parts of Ethiopia; Gorche (10.6\%), Kamba (23.3\%), and Wolaita (43.2\%). Similarly, better than findings from Tanzania (38.2\%), and Southern Asian countries namely; India(15\%), Nepal (34\%) and Bangladesh (42\%) $(5,9-11,15,16)$. This difference might be this study done in rural area where livestock, agricultural land and plot gardening land is more than $70 \%$ available. Food security status also relatively good (70.8\%) in this area. However the finding was lower than study done in the capital city of Ethiopia (59.9\%) and one of Southern Asian country Sri Lanka (71\%) $(16,17)$. This relatively lower result might be related with the lower $(9.7 \%)$ number of mothers were attended college/university in this study, which might affect the understanding level of mothers about diversified diet importance. Similarly, both studies done in urban area where knowledge of mothers were higher which significantly associated with improved feeding habit of diversified diet(18).

Mothers within the age group of 18-24 years were 3.68 times more likely to fed on adequately diversified diet for their children than mothers who were older than 32 years. This might be related with the higher tendency of young mothers to utilize PNC service over the old once; so, they can get counseling service on proper child feeding practices at postnatal checkup. But this finding disagree with the finding of one of the Oromia region district; reported mothers' dietary diversity feeding habit increases with maternal age(18). The disagreement might be related with maternal knowledge difference towards dietary diversity.

Mothers who followed PNC service were 8.8 times more likely to feed adequately diversified diet to their children than those who did not follow the service. This result is similar with the findings from Dabat 
district northwest Ethiopia, Afar region, a systematic review and metanalysis done in Ethiopia, Tanzania, and with the study done across five South Asian countries $70(15,16,19-21)$. This might be due to the guidance and counseling service that mothers received from health workers during their postnatal visits which may also include advice about best dietary diversity feeding practices.

Children within the age group 6-11 months were 2 times more likely to be fed on adequately diversified diet as compared to children in the age group 18-23 months. This finding is compatible with Wolaita district, South Ethiopia finding. However, incompatible with the findings of a secondary analysis of Ethiopian demographic and health survey 2011, and Tanzania, where older children were more likely to be fed on adequately diversified diet $(8,15)$. This might be due to the fact that in the study area when children grow older they join their family diet which usually is a monotonous type. In addition to this, lesser attention might be given to older children.

Mothers from food secured $\mathrm{HHs}$ were 3.64 times more likely to give minimum dietary diversity to their children than those mothers who were from food insecure HHs. In favor of this finding study done in South Africa indicated $\mathrm{HHs}$ with low dietary diversity were more food insecure than $\mathrm{HHs}$ with a higher dietary diversity(22). This result was consistent with the finding from rural Bangladesh(23). This might be related with the better $\mathrm{HH}$ food security status was associated with better infant and young children feeding practices; consequently dietary diversity score improved (24).

On the other hand, this study revealed that there was no association between ANC visit and dietary diversity. But this finding disagrees with study done in Wondo district, and a systematic review and metanalysis done in Ethiopia, $(20,25)$ where lack of ANC follow up was significant factors for MDD feeding practice. This shows that health professionals providing ANC were more focused on the pregnancy related information than child feeding practices.

Similarly, maternal education level was not associated with dietary diversity in this study, which is inconsistent with finding from Afar Region reported maternal education was independently associated with $\operatorname{MDD}(26)$. The lack of association may be attributed to the less attention is given to nutrition education. The strength and limitation of this study respectively was; the study done in rural setting of southern Ethiopia and a twenty-four-hour dietary recall may not accurately reflect maternal past feeding experience.

\section{Conclusions}

Dietary diversity among children aged from 6-23 months were low in the rural setting. Maternal age, child age, PNC follow-up and HH food security status were found as primary factors to affect dietary diversity. Post-natal care services outlets should be used to transmit child feeding information hence; training should be provided by concerned body pertaining to proper child feeding practices with main emphasis to meet the MDD. In addition, agricultural sector should strengthen implementation of nutrition sensitive agriculture to ensure HHs to be food secured to feed their children on diversified diets. Finally, 
farther study should be conducted to measure dietary adequacy by measuring (weighting) foods consumed by infants and young children per 24 hours in the district.

\section{Declarations}

\section{Ethics approval and consent to participate}

Ethical clearance and approval were obtained from Wolaita Sodo University Ethical Review Committee. Then permission and support letter was written to respective Kebeles by Kacha Bira district administrative health office. The objective of the study and their right to refuse was well explained to all mothers/caretakers. Furthermore, the confidentiality of the information collected was assured to each participant. Their informed written consent was secured prior to the commencement of data collection. During data collection no financial provision was made and rights or welfare of the study subjects were respected.

\section{Consent for publication}

Not applicable.

\section{Availability of data and materials}

The datasets used and/or analyzed during this study are available from the corresponding author and provided on a reasonable request.

\section{Competing interests}

The authors declare that they have no competing interests.

\section{Funding}

This study was funded by Wolaita Sodo University. The funder had no role in the conception, study design, data collection, analysis, writing manuscript and decision to publish.

\section{Authors' contributions}

BG was involved in the conception, design, analysis, interpretation, report and manuscript writing. SB, TB, and TD were involved in the design, analysis, interpretation, report and manuscript writing. All authors read and approved the final manuscript.

\section{Acknowledgments}

We would like to thank Wolaita Sodo University granted the study. And we also extend our gratitude to data collectors and supervisors.

\section{Authors' information}


BG is Coordinator, Kenbata Tembaro zonal health department, Durame, Ethiopia; SB, TB, and TD are lecturers, School of Public Health, College of Health Sciences and Medicine, Wolaita Sodo University, Wolaita Sodo, Ethiopia.

\section{Abbreviations}

ANC: Antenatal Care, AOR: adjusted odds ratio, Cl: Confidence Interval; EDHS: Ethiopia Demographic and Health Survey; ETB: Ethiopian Birr, HH: Household, MDD: Minimum Dietary Diversity; PNC: Postnatal Care; SPSS: Statistical Package for Social Sciences; WHO: World Health Organization.

\section{References}

1. WHO. Indicators for assessing infant and young child feeding practices part 1 definitions: conclusions of a consensus meeting held 6-8 November 2007 in Washington D.C., USA.

2. Institute IFPR, editor Is dietary diversity an indicator food security or dietary quality? a review of measurement issues and research needs. FCND discussion paper no 140; November 2002; Washington, D.C. 20006 U.S.A.

3. WHO. Indicators for assessing infant and young child feeding practices part 2: measurement. 2010.

4. FDRE. National Nutrition Program 2016-2020.

5. EDHS. Ethiopia Demographic and Health Survey 2016. Addis Ababa, Ethiopia: CSA, July 2017.

6. UNICEF. A World Fit for Children. 2006.

7. Gebremedhin S. Core and optional infant and young child feeding indicators in Sub-Saharan Africa: a crosssectional study. BMJ Open. 2019;9:e023238. doi:10.1136/.

8. Melkam Aemro MM, Zelalem Birhanu, Azeb Atenafu. Dietary Diversity and Meal Frequency Practices among Infant and Young Children Aged 6-23 Months in Ethiopia: A Secondary Analysis of Ethiopian Demographic and Health Survey 2011. Journal of Nutrition and Metabolism. 2013 http://dx.doi.org/10.1155/2013/782931.

9. Dangura D GS. Dietary diversity and associated factors among children 6-23 months of age in Gorche district, Southern Ethiopia: Cross-sectional study. BMC pediatrics. 2017;17:6.

10. Gamo G AM. Dietary Diversity and Associated Factors Among Infants and Young Children in Wolaita Zone, Southern Ethiopia. Science Journal of Clinical Medicine. 2017;6(4):53-9.

11. Gatahun EA DM, Abyu DM. Dietary Diversity Feeding Practice and Determinants among Children Aged 6-23 Months in Kemba Woreda, Southern Ethiopia Implication for Public Health Intervention. Journal of Nutrition \& Food Sciences. 2015.

12. District Health Office. Health report. 2018.

13. Agriculture and natural resources office. Agriculture and natural resources report. 2018.

14. FANTA. Household Food Insecurity Access Scale (HFIAS) for Measurement of Food Access: Indicator Guide. August 2007. 
15. Victor R. Factors associated with inappropriate complementary feeding practices among children aged 6-23 months in Tanzania. Maternal and Child Nutrition. 2014;10:545-61.

16. Senarath U. Comparisons of complementary feeding indicators and associated factors in children aged 6-23 months across five South Asian countries. Maternal and Child Nutrition 2012;8:89-106.

17. Solomon D. Minimum dietary diversity and associated factors among children aged 6-23 months in Addis Ababa, Ethiopia. International Journal for Equity in Health. 2017;16:181.

18. Agize A. Level of Knowledge and Practice of Mothers on Minimum Dietary Diversity Practices and Associated Factors for 6-23-Month-Old Children in Adea Woreda, Oromia, Ethiopia. BioMed Research International. 2017:9.

19. Liben ML. Factors Associated with Dietary Diversity among Children of Agro Pastoral Households in Afar Regional State, Northeastern Ethiopia. Academic Journal of Pediatrics \& Neonatology. 2017;5(2).

20. Temesgen $\mathrm{H}$. Dietary diversity feeding practice and its associated factors among children age 6-23 months in Ethiopia from 2011 up to 2018: a systematic review and metaanalysis. Italian Journal of Pediatrics. 2018;44:109.

21. Belew AK. Dietary diversity and meal frequency among infant and young children: a community based study. Italian Journal of Pediatrics. 2017;43(73).

22. Faber M. Dietary diversity in relation to other household food security indicators. Int J Food Safety, Nutrition and Public Health. 209;2(1).

23. Ali NB. Association of food security and other socio-economic factors with dietary diversity and nutritional statuses of children aged 6-59 months in rural Bangladesh. PLoS ONE 2019;14(8).

24. Lindsay AC. Child feeding practices and household food insecurity among low-income mothers in Buenos Aires, Argentina. Ciência \& Saúde Coletiva. 2012;17(3):661-9.

25. Karisa Dafursa SG. Dietary Diversity among Children Aged 6-23 Months in Aleta Wondo District, Southern Ethiopia. Journal of Nutrition and Metabolism. 2019:10.

26. Wuneh AG. Dietary Diversity and Meal Frequency Practices among Children Aged 6-23 Months in Agro Pastoral Communities in Afar Region, Ethiopia: A Cross-sectional Study. Journal Ecology of Food and Nutrition 2019;58(6):575-96.

\section{Tables}

Table 1. Socio-demographic and economic characteristics of mothers in rural community of Kacha Bira district, Southern Ethiopia, February, 2018(n=616) 


\begin{tabular}{|c|c|c|}
\hline Variables & Frequency $(\mathrm{N})$ & Percent (\%) \\
\hline \multicolumn{3}{|l|}{ Maternal age } \\
\hline $18-24$ & 167 & 27.1 \\
\hline $25-32$ & 229 & 37.2 \\
\hline$>32$ & 220 & 35.7 \\
\hline \multicolumn{3}{|l|}{ Maternal marital status } \\
\hline Married & 610 & 99 \\
\hline Divorced/widowed & 6 & 1 \\
\hline \multicolumn{3}{|l|}{ Maternal occupational status } \\
\hline House wife & 529 & 85.9 \\
\hline Daily laborer/merchant & 63 & 10.2 \\
\hline Employee & 24 & 3.9 \\
\hline \multicolumn{3}{|l|}{ Maternal educational status } \\
\hline No formal education & 232 & 37.7 \\
\hline Primary education complete & 209 & 33.9 \\
\hline Secondary education complete & 115 & 18.7 \\
\hline College/university & 60 & 9.7 \\
\hline \multicolumn{3}{|l|}{ Paternal occupational status } \\
\hline Farmer & 436 & 70.8 \\
\hline Merchant & 58 & 9.4 \\
\hline Employee & 57 & 9.2 \\
\hline Daily laborer & 65 & 10.6 \\
\hline \multicolumn{3}{|l|}{ Paternal educational status } \\
\hline No formal education & 185 & 30 \\
\hline Primary education complete & 215 & 34.9 \\
\hline Secondary education complete & 147 & 23.9 \\
\hline College/university & 69 & 11.2 \\
\hline \multicolumn{3}{|l|}{ Parity } \\
\hline 1 & 135 & 21.9 \\
\hline $2-4$ & 295 & 47.9 \\
\hline $5-6$ & 107 & 17.4 \\
\hline 7 and above & 79 & 12.8 \\
\hline \multicolumn{3}{|l|}{ Family size } \\
\hline $2-3$ & 154 & 25 \\
\hline $4-6$ & 377 & 61.2 \\
\hline 7 and above & 85 & 13.8 \\
\hline
\end{tabular}


Family income/monthly

\begin{tabular}{|c|c|c|}
\hline$<=999$ & 453 & 73.5 \\
\hline 1000-1999 ЕТВ & 94 & 15.3 \\
\hline 2000-2999 ЕТВ & 43 & 7 \\
\hline 3000-3999 ЕТВ & 19 & 3.1 \\
\hline$>=4000$ & 7 & 1.1 \\
\hline
\end{tabular}

Table 2. Food security status of households in rural community of Kacha Bira district, Southern Ethiopia, February, 2018(n=616)

\begin{tabular}{lcc}
\hline Household food security status & Number(N) & Percent (\%) \\
\hline Food secure & 436 & 70.8 \\
Mildly food insecure & 28 & 4.6 \\
Moderately food insecure & 39 & 6.3 \\
Severely food insecure & 113 & 18.3 \\
\hline
\end{tabular}

Table 3. Own production and home gardening of respondents in rural community of Kacha Bira district, Southern Ethiopia, February, 2018(n=616) 
Households having a plot

$\begin{array}{lll}\text { Yes } & 432 & 70.1 \\ \text { No } & 184 & 29.9\end{array}$

Having livestock

Yes
No

455

73.9

161

26.1

Having agricultural land

Yes

576

93.5

No

40

6.5

Availability of fruits and vegetables in the markets

Yes

357

58

No

259

42

Availability of meat, milk and fish in the markets

Yes

246

39.9

No

370

60.1

Households getting milk from own cow

Yes

177

28.7

No

439

71.3

Households getting eggs from own chicken

Yes

155

25.2

No

461

74.8

Table 4-Maternal health care services in rural community of Kacha Bira district, Southern Ethiopia, February, 2018(n=616) 


\begin{tabular}{|c|c|c|}
\hline Variables & Frequency $(\mathrm{N})$ & Percent (\%) \\
\hline \multicolumn{3}{|l|}{ Place of delivery } \\
\hline Hospital & 203 & 33 \\
\hline Health center & 353 & 57.3 \\
\hline Health post & 4 & 0.6 \\
\hline Home & 56 & 9.1 \\
\hline \multicolumn{3}{|c|}{ ANC Follow up with last child } \\
\hline Yes & 604 & 98.1 \\
\hline No & 12 & 1.9 \\
\hline \multicolumn{3}{|c|}{ PNC Follow up with last child } \\
\hline Yes & 441 & 71.6 \\
\hline No & 175 & 28.4 \\
\hline \multicolumn{3}{|l|}{ Radio follow up } \\
\hline Always & 283 & 45.9 \\
\hline Sometimes & 184 & 29.9 \\
\hline Never & 149 & 24.2 \\
\hline
\end{tabular}

Table 5 Characteristics of Indexed Child in rural community of Kacha Bira district, Southern Ethiopia, February, 2018(n=616) 


\section{Variables}

Sex of the child

Male

Female
18-23 months

6-11 months

12-17 months

18-23 months

Birth order of the child

First

2-4

Above 4

Health status of the child

Healthy

580

36

Sick
300

316

229

210

177

48.7

51.3

37.2

34.1

28.7

153

24.8

309

50.2

154

25

Vaccinated status

Yes

No
527

89
85.6

14.4

Table 6. Factors associated with minimum dietary diversity among 6-23 months children in rural community of Kacha Bira district, Southern Ethiopia, February, 2018(n=616) 


$\begin{array}{llll}\text { Achieved } & \text { Not achieved } & \text { COR(95\% C.I } & \text { AOR(95\%C.I) } \\ \mathrm{N}(\%) & \mathrm{N}(\%) & \end{array}$

Maternal age

$\begin{array}{lllll}18-24 & 110(66.6) & 57(33.4) & 4.31(2.81,6.62) & 3.68(1.18,6.22)^{*} \\ 25-32 & 106(46.3) & 123(53.7) & 1.93(1.48,3.38) & 1.86(1.20,3.22)^{*} \\ >32 & 68(30.9) & 152(69.1) & 1.00 & 1.00\end{array}$

Maternal

occupation

House wife

Daily

241(45.6) 288(54.4)

1.00

1.00

27(42.8) 36(57.2)

$2.67(1.70,0.14)$

$2.24(0.80,6.21)$

laborer/merchant

Employee

16(66.7) 8(33.3)

$2.39(1.01,5.68)$

$1.58(0.46,5.39)$

Maternal education

College/University

$30(50) \quad 30(50)$

$1.50(0.85,2.64) \quad 1.72(0.70,4.17)$

Secondary

60(52) 55(48)

$1.49(0.38,1.18)$

$1.59(0.68,3.73)$

education

Primary education

101(50) 108(50)

$1.39(0.39,1.96)$

$1.35(0.58,3.16)$

No formal

93(40)

139(60)

1.00

1.00

education

Paternal education

College/University

42(60.9) 27(39.1)

$2.18(1.01,3.24)$

$1.45(0.71,2.97)$

Secondary

68(45.1) 79(54.9)

$1.89(1.20,3.29)$

$1.20(0.59,2.42)$

education

Primary education

$97(45.5)$

118(54.5)

$1.80(0.58,1.29)$

$1.06(0.51,2.23)$

No formal

77(41.6)

108(58.4)

1.00

1.00

education

Postnatal care

follow up

Yes

262(59.4) 179(40.6)

$10.18(6.26,16.54)$

$8.80(5.17,14.98) *$ 
No

22(12.6) 153(87.4)

1.00

1.00

Child age in month

$\begin{array}{lllll}6-11 & 117(51.1) & 112(48.9) & 2.13(1.42,3.19) & 2.04(1.24,3.39)^{*} \\ 12-17 & 102(48.6) & 108(51.4) & 1.19(0.82,1.73) & 1.44(0.91,2.29) \\ 18-23 & 65(36.7) & 112(63.3) & 1.00 & 1.00 \\ \text { Having livestock } & & & & \\ \text { Yes } & 223(49) & 232(51) & 1.58(1.09,2.28) & 1.32(0.79,2.17) \\ \text { No } & 61(37.9) & 100(62.1) & 1.00 & \end{array}$

Having own milk

cow

Yes

104(58.8) 73(41.2)

$2.05(1.44,2.92) \quad 1.59(0.98,2.59)$

No

180(41.2) 259(59)

1.00

1.00

Plot for home

gardening

Yes

210(48.6) 222(51.4)

$1.41(0.99,1.99)$

$1.25(0.79,1.95)$

No

74(40.2) 110(59.8)

1.00

1.00

Egg from own

chicken

Yes

90(58.1) 65(41.9)

$1.91(1.32,2.76)$

$1.27(0.79,2.05)$

No

194(42.1) 267(57.9)

1.00

1.00

$\mathrm{HH}$ food security

status

Food secure

246(56.4) 190(43.6)

$4.84(3.2,7.25)$

$3.64(2.27,5.84)^{*}$

Food insecure

38(21.1) 142(78.9)

1.00

1.00

* indicate significant at p-value $<0.05$

\section{Figures}




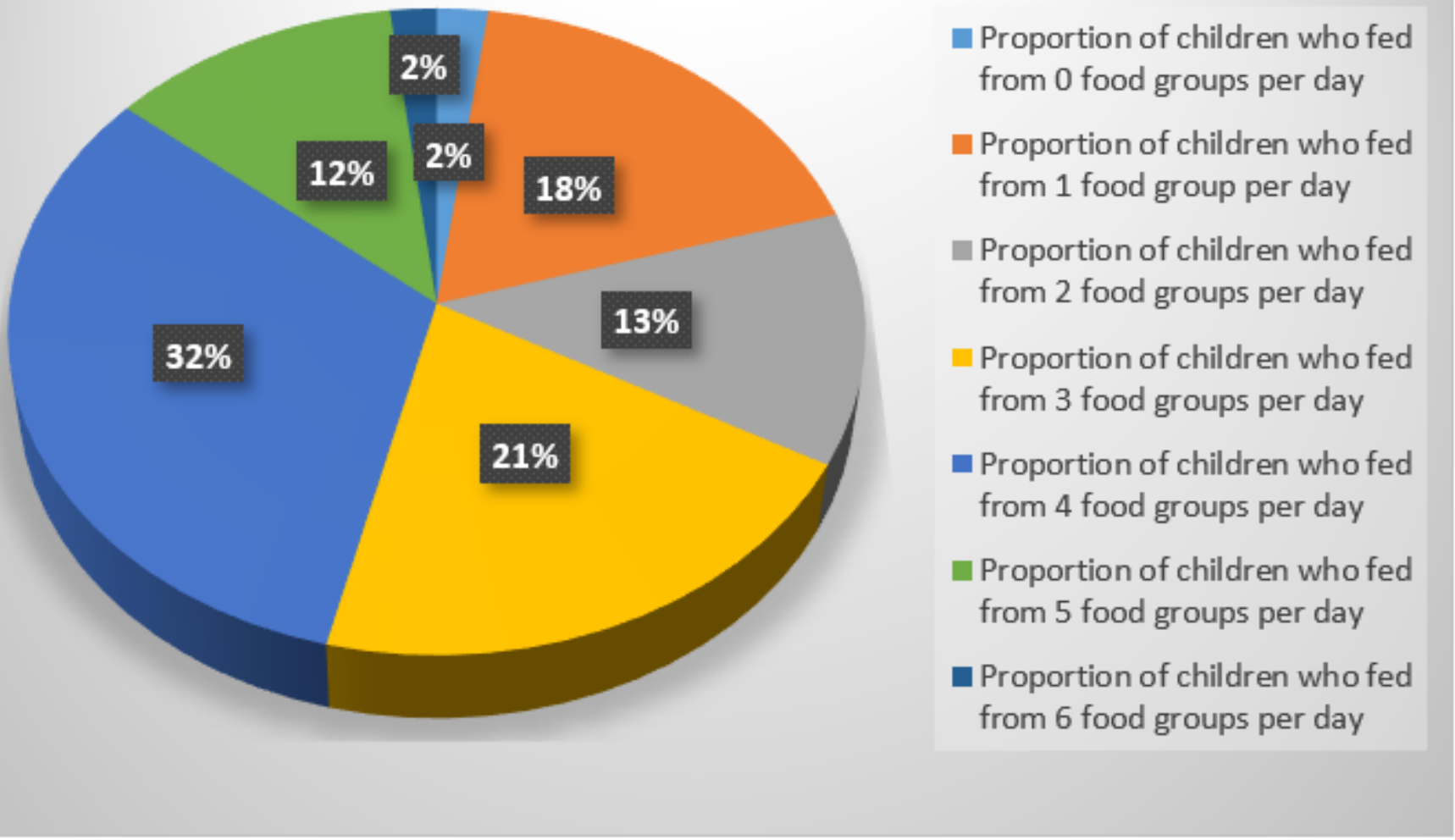

Figure 1

Proportion of 6-23 months children who fed on different food groups from $24 \mathrm{hrs}$ recall in rural community of Kacha Bira district, Southern Ethiopia, February, 2018(n=616) 


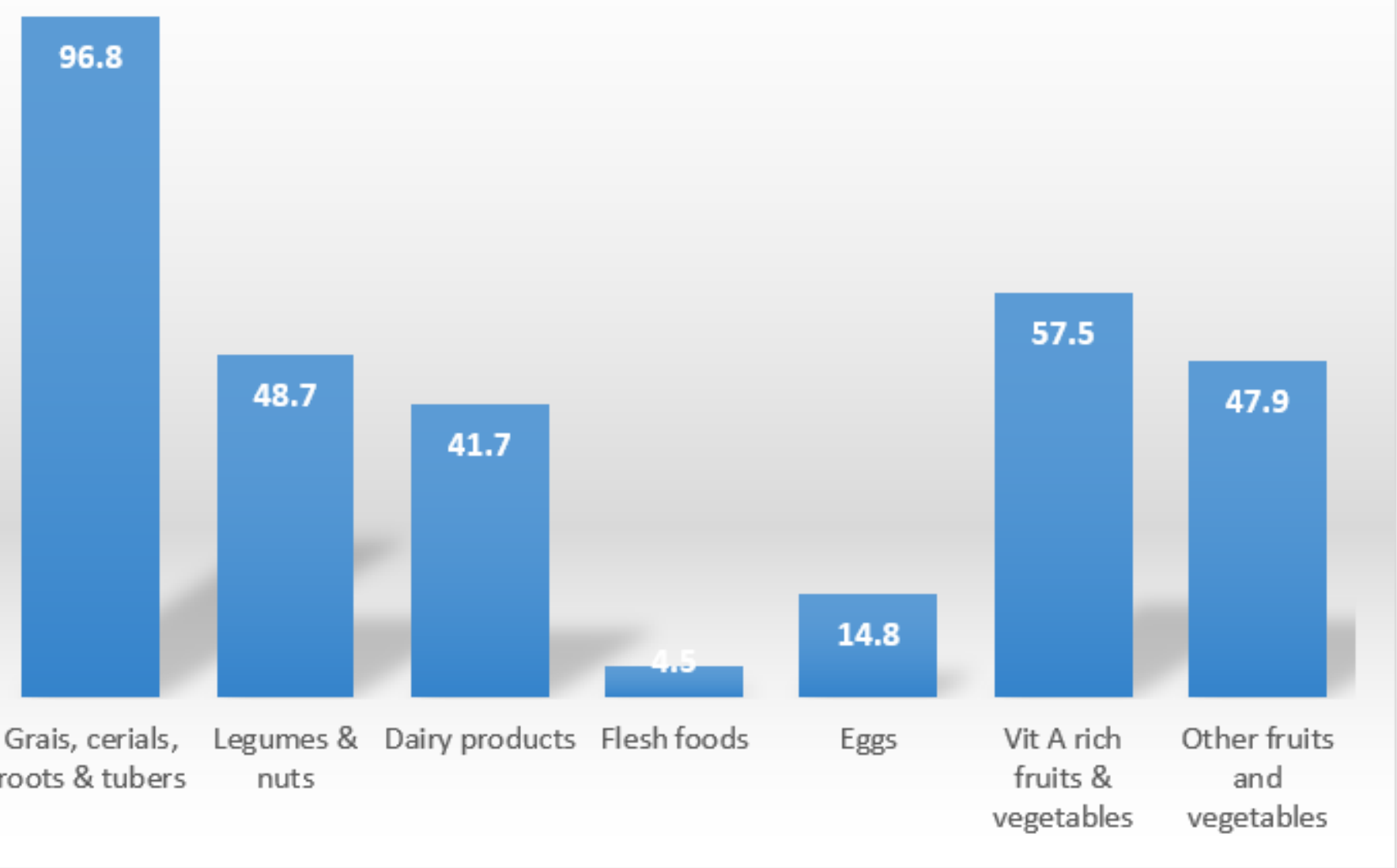

Figure 2

Types of food groups consumed by indexed children assessed by 24-hour recall in rural community of Kacha Bira district, Southern Ethiopia, February, 2018(n=616) 